\title{
Speed Control of PMSM Drive fed with Nine Level Inverter
}

\author{
R. Sasidhar, A. Lakshmi Devi
}

\begin{abstract}
Power electronic technology made possible to evolve inverter fed electric drives. Permanent magnet synchronous motors (PMSM) are in much importance and are used often due to its performance characteristics. PMSM gives less noisy operation with faster and more efficient operation. PMSM needs a digital inverter for its operation. The paper analyzes nine-level inverter fed PMSM drive. Multi-carrier level-shifted technique is used to generate control pulses. Simulation work of the proposed concept is carried out and the results are presented using MATLAB/SIMULINK software.
\end{abstract}

Index Terms: PMSM, Multi-Level Inverter, LSCPWM, Speed control

\section{INTRODUCTION}

For many of the applications in agriculture and industries, use of motors to drive mechanical loads is been increased. Motor is used to reduce the human efforts when working with mechanical type of loads. Motor is a device which converts electrical energy to mechanical energy. Motors can be broadly classified as AC and DC motors. Use of commutator and brushes in DC motors pushes them back against other type of motors though they have good performance characteristics. Induction motors and synchronous motors are well known types of AC motors. Induction motor contains rotor coils and stator coils for its operation which eventually affects the power factor and increases the use of copper giving out losses with reduced efficiency of the system. Permanent magnet synchronous motor (PMSM) [1-4] is a synchronous motor uses only permanent magnets on its rotor and windings on its stator.

Stator windings of PMSM are distributed winding and the back EMF (BEMF) is sinusoidal in shape [7-10]. No coils will be wounded on rotor circuit. This makes usage of PMSM in many applications over other type of motors [5-7]. Current flow in each winding (when excited) produces a magnetic field vector, which sums with the fields from the other windings. By controlling currents in the stator windings, a magnetic field of arbitrary direction and magnitude is produced by the stator. Torque is then produced by the attraction or repulsion between this net stator field and the magnetic field of the rotor.

Conventional inverters give out square wave alternating output voltage consisting of high distortion. Alternating quantity with high distortion cannot be fed to any device and needs smoothing filters. Inverters are made up of capacitors and inductors which make the output current smooth as compared to switching square wave output we get with a conventional inverter. If the distortion quantity is high, filter size also increases. This phenomenon led to development of multi-level inverters [8-10].

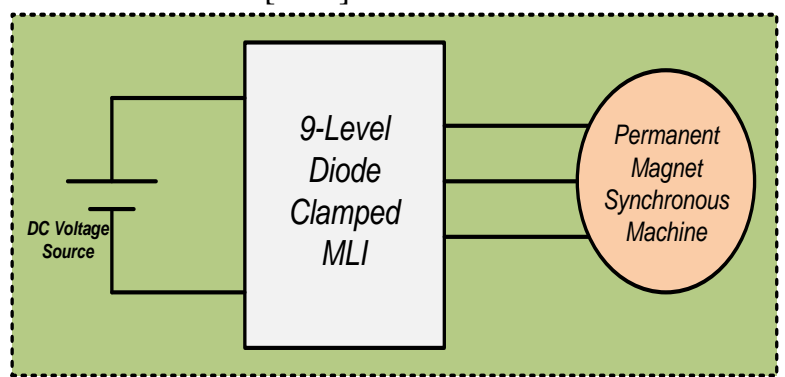

Figure 1: Representation of 9-level inverter fed PMSM

Multi-level inverters became the prior pick for high power high voltage applications. Multi-level inverters are able to generate high voltage with lower rated devices. Multi-level inverter generates leveled (stepped) output and as the number of level increases better output voltage waveform is obtained. Diode clamped multi-level inverters are one among multi-level topologies and uses diodes as clamping elements. Multi-level inverter driven PMSM is shown in figure 1.

PMSM needs a digital inverter for its operation. The paper analyzes nine-level inverter fed PMSM drive. Multi-carrier level-shifted technique is used to generate control pulses. Simulation work of the proposed concept is carried out and the results are presented using MATLAB/SIMULINK software.

\section{PROPOSED NINE-LEVEL DIODE-CLAMPED INVERTER FED PMSM DRIVE}

Multilevel inverters (MLI) are becoming increasingly popular in power applications, as multilevel inverters have the ability to meet the increasing demand of power rating and power quality associated with reduced harmonic distortion and lower electromagnetic interference. Multilevel inverters are capable of generating output voltage with very low harmonic distortion with low dv/dt. Diode clamped MLI (DCMLI) shown in figure 2 or also called as neutral point clamped MLI is one of the topology of multi-level structure. Diodes, capacitors plays important role in the operation of generating multi-level output from diode-clamped inverter. Diode-clamped inverter presents only half the amount of input voltage at the output.

Dr. A. Lakshmi Devi, Professor, Department of Electrical \& Electronics Engineering, Sri Venkateswara University College of Engineering, Tirupati, AP, India 


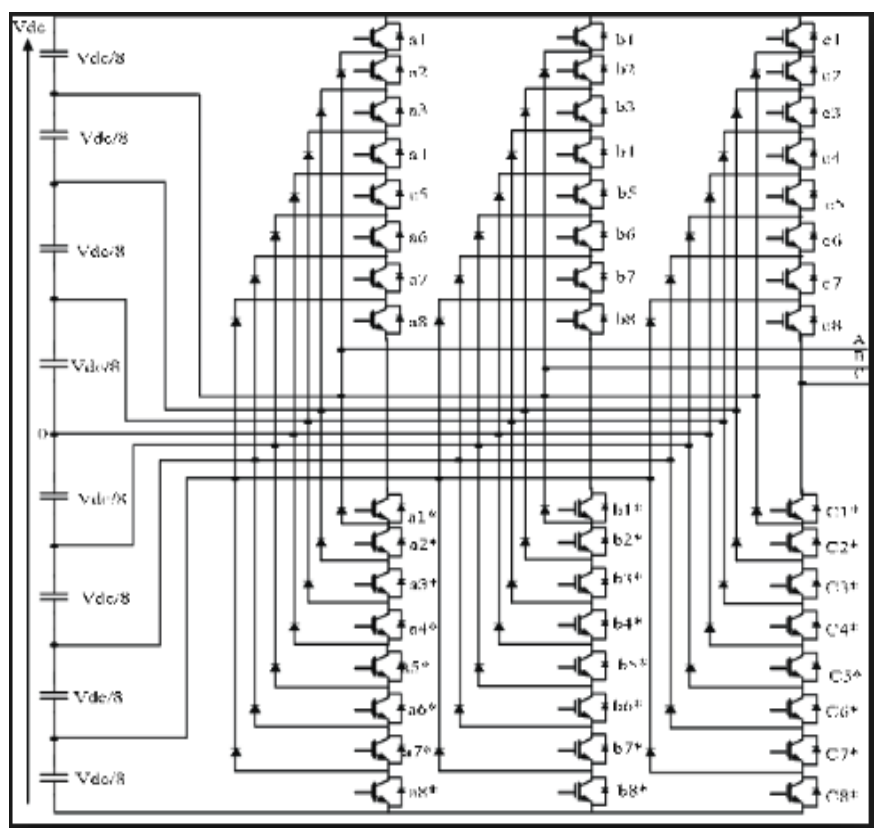

Figure 2: 9-level diode clamped inverter

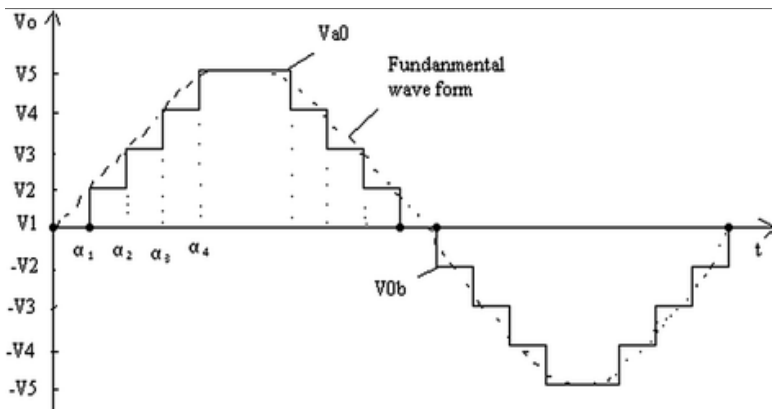

Figure 3: Output of 9-level DCMLI

Table-1: Switching pattern for 9-level DCMLI

\begin{tabular}{|c|c|c|c|c|c|c|c|c|}
\hline Volt & A1 & A2 & A3 & A4 & A5 & A6 & A7 & A8 \\
\hline V9 & 1 & 1 & 1 & 1 & 1 & 1 & 1 & 1 \\
\hline V8 & 0 & 1 & 1 & 1 & 1 & 1 & 1 & 1 \\
\hline V7 & $\mathbf{0}$ & $\mathbf{0}$ & 1 & 1 & 1 & 1 & 1 & 1 \\
\hline V6 & $\mathbf{0}$ & $\mathbf{0}$ & $\mathbf{0}$ & 1 & 1 & 1 & 1 & 1 \\
\hline V5 & $\mathbf{0}$ & $\mathbf{0}$ & $\mathbf{0}$ & $\mathbf{0}$ & 1 & 1 & 1 & 1 \\
\hline V4 & $\mathbf{0}$ & $\mathbf{0}$ & $\mathbf{0}$ & $\mathbf{0}$ & $\mathbf{0}$ & 1 & 1 & 1 \\
\hline V3 & $\mathbf{0}$ & $\mathbf{0}$ & $\mathbf{0}$ & 0 & $\mathbf{0}$ & $\mathbf{0}$ & 1 & 1 \\
\hline $\mathrm{V2}$ & $\mathbf{0}$ & $\mathbf{0}$ & $\mathbf{0}$ & $\mathbf{0}$ & $\mathbf{0}$ & $\mathbf{0}$ & $\mathbf{0}$ & 1 \\
\hline V1 & $\mathbf{0}$ & $\mathbf{0}$ & $\mathbf{0}$ & $\mathbf{0}$ & 0 & 0 & 0 & $\mathbf{0}$ \\
\hline Volt & A1* & A2* & A3* & A4* & A5* & A6* & A7* & A8* \\
\hline V9 & 0 & 0 & $\mathbf{0}$ & $\mathbf{0}$ & 0 & 0 & $\mathbf{0}$ & $\mathbf{0}$ \\
\hline V8 & 1 & $\mathbf{0}$ & $\mathbf{0}$ & $\mathbf{0}$ & $\mathbf{0}$ & $\mathbf{0}$ & $\mathbf{0}$ & $\mathbf{0}$ \\
\hline V7 & 1 & 1 & $\mathbf{0}$ & $\mathbf{0}$ & $\mathbf{0}$ & $\mathbf{0}$ & $\mathbf{0}$ & $\overline{0}$ \\
\hline V6 & 1 & 1 & 1 & $\mathbf{0}$ & $\mathbf{0}$ & $\mathbf{0}$ & $\mathbf{0}$ & $\mathbf{0}$ \\
\hline V5 & 1 & 1 & 1 & 1 & $\mathbf{0}$ & $\mathbf{0}$ & $\mathbf{0}$ & $\mathbf{0}$ \\
\hline V4 & 1 & 1 & 1 & 1 & 1 & $\mathbf{0}$ & $\mathbf{0}$ & $\mathbf{0}$ \\
\hline V3 & 1 & 1 & 1 & 1 & 1 & 1 & $\mathbf{0}$ & 0 \\
\hline $\mathrm{V2}$ & 1 & 1 & 1 & 1 & 1 & 1 & 1 & $\mathbf{0}$ \\
\hline V1 & 1 & 1 & 1 & 1 & 1 & 1 & 1 & 1 \\
\hline
\end{tabular}

Published By:

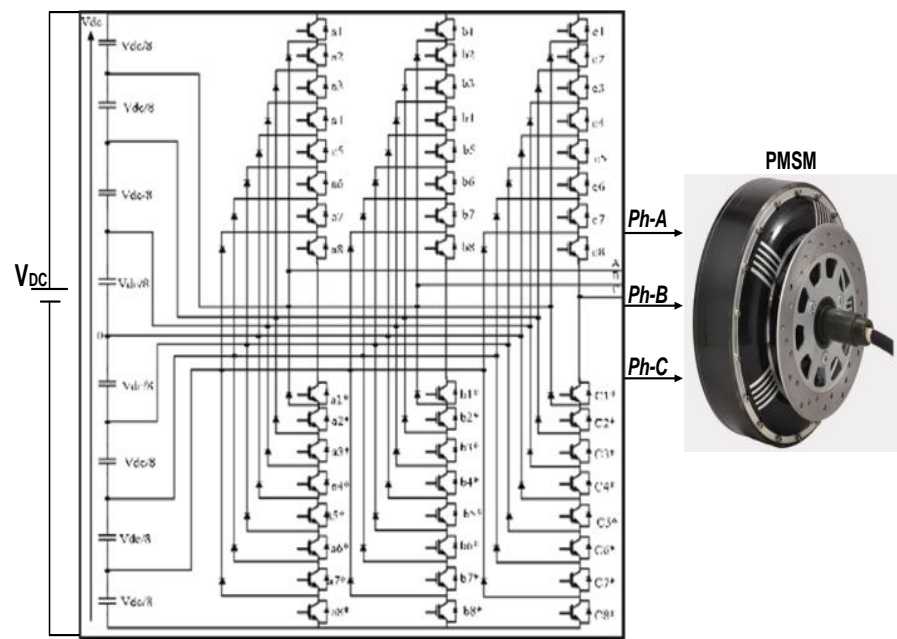

Figure 4: 9-level DCMLI fed PMSM

Figure 3 shows the output obtained from 9-level DCMLI and table-I shows switching pattern of 9-level DCMLI. Figure 4 shows the 9-level DCMLI fed PMSM.

III. CONTROL STRATEGY

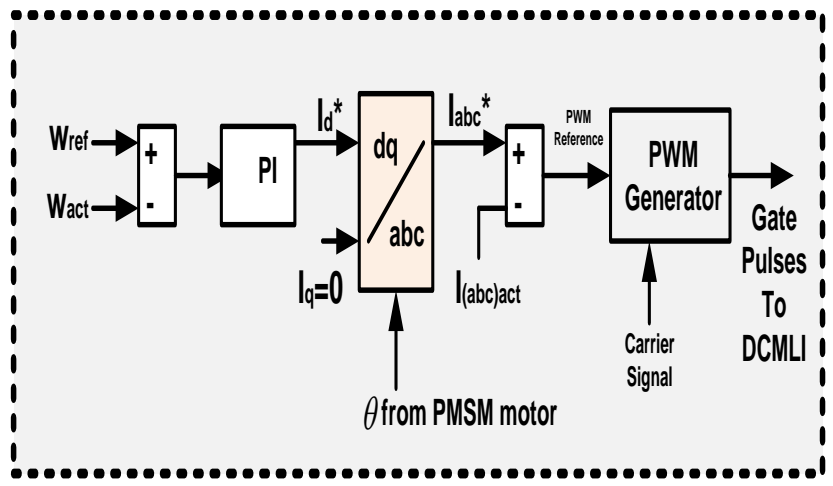

Figure 5: Speed control of PMSM fed from DCMLI

In speed control operation of PMSM drive, initially the actual speed of the PMSM is compared to reference speed value. Actual speed is measured by speed sensors. Error signal is sent to PI controller to obtain reference d-axis current. Reference q-axis current is considered to be zero. Then, 'dq' coordinates are transformed to 'abc' coordinates giving out reference current signal. The reference current signal obtained is compared to actual current from the PMSM which gives out the PWM reference signal. Relational operated PWM reference and carrier signals using LSCPWM pattern generated gate pulses to the diode clamped inverter. Figure 6 shows the complete schematic arrangement of 9-level DCMLI fed PMSM with control. 


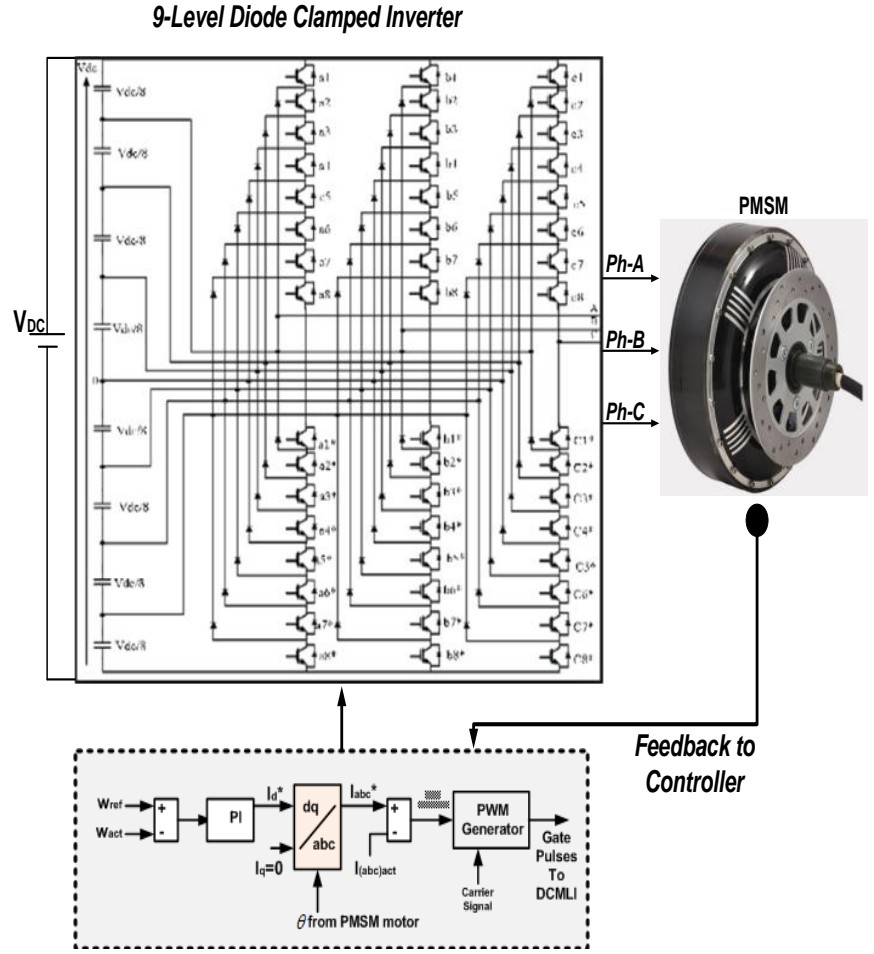

Figure 6: 9-level DCMLI fed PMSM with control

\section{SIMULATION RESULTS}

A. PMSM with fixed speed

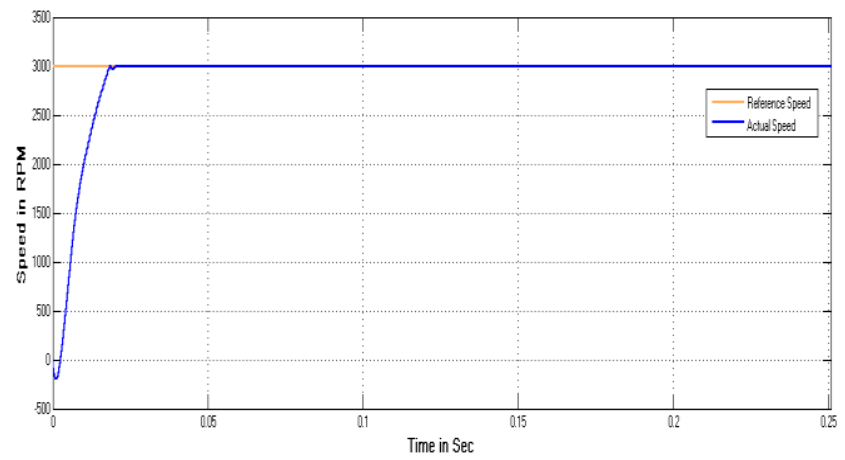

Figure 7: Speed of PMSM drive

Speed of PMSM running with fixed speed condition is shown in figure 7. Reference speed signal and the actual speed (in blue) signal are shown in figure 7 . The actual speed follows the reference speed 3000 RPM. Actual speed rises to final value and PMSM runs at constant 3000 RPM.

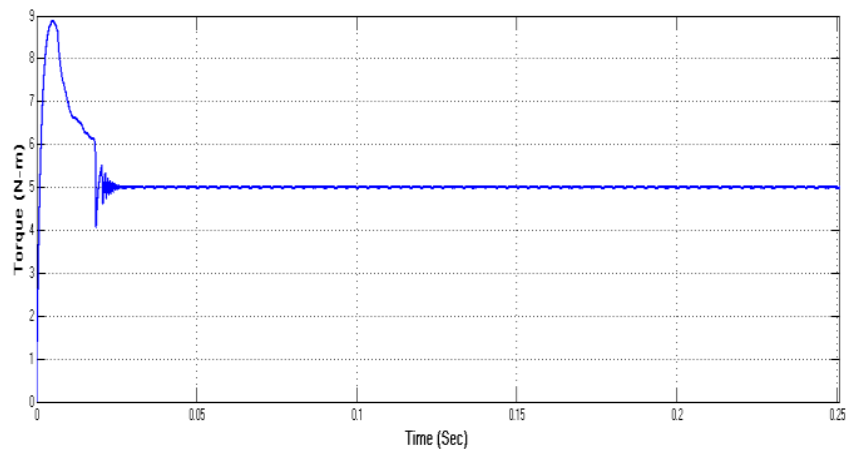

Figure 8: Torque of PMSM drive

Figure 8 shows the torque of PMSM. PMSM generates torque of $5 \mathrm{~N}-\mathrm{m}$ corresponding to $3000 \mathrm{RPM}$. After initial transient in torque, the signal remains constant with $5 \mathrm{~N}-\mathrm{m}$. As the speed is maintained constant, torque also remains constant.

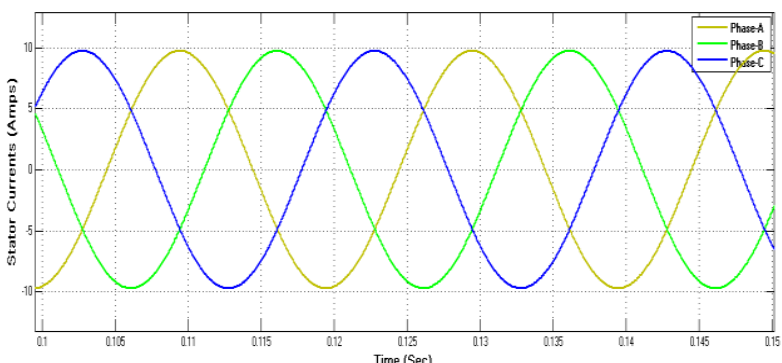

Figure 9: Three-Phase stator currents of PMSM
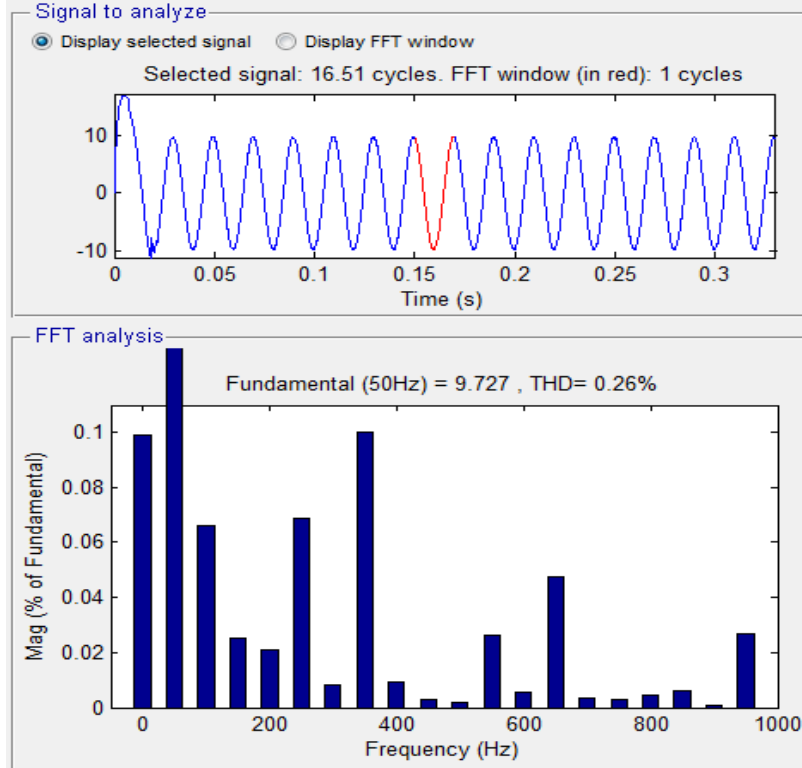

Figure 10: THD in stator current

Figure 9 illustrates three-phase stator currents of PMSM. Three-phase PMSM stator coils draws 10A current. Magnitude in three phases of stator coils remains with constant peak. Harmonic distortion FFT window of stator current is shown in figure 10. Stator current is distorted by $0.26 \%$ and is well within nominal distortion limits.

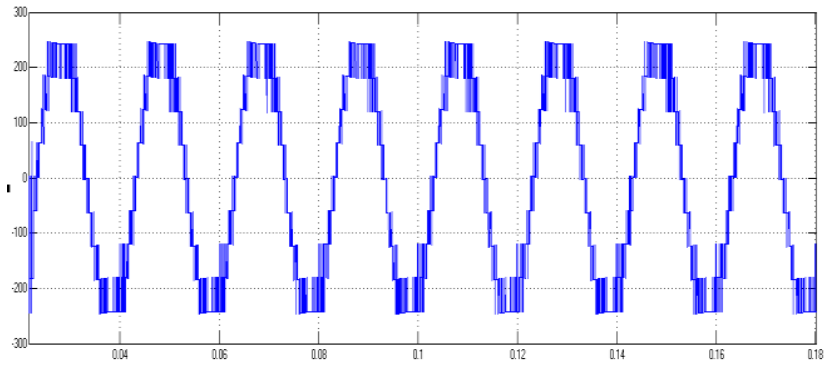

Figure 11: Three-Phase voltages of DCMLI 


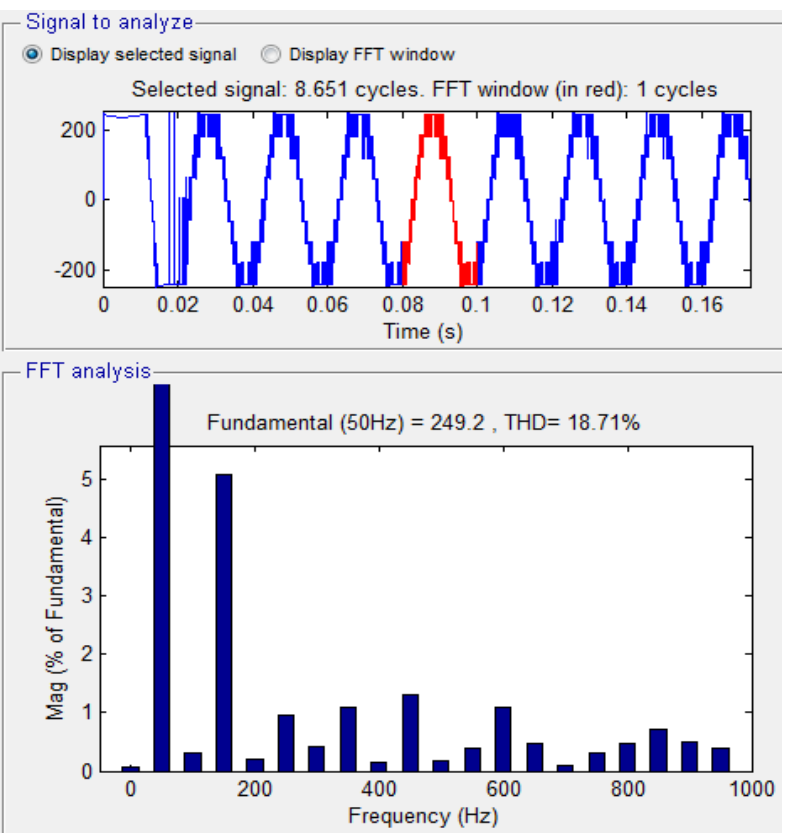

Figure 12: THD in phase voltage of DCMLI

Figure 11 illustrates three phase voltages of diode clamped inverter. Phase voltage is leveled with nine magnitudes yielding nine-level voltage signal. Peak magnitude of phase voltage in three phases is $250 \mathrm{~V}$. Harmonic analysis in phase voltage signal is shown in figure 12 . FFT window displayed shows $18.71 \%$ distortion in phase voltage of DCMLI.

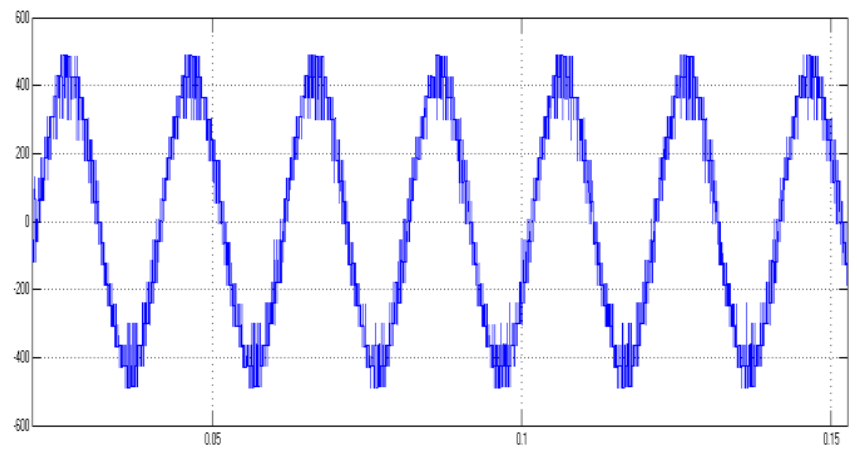

Figure 13: Three-Phase Line voltages of DCMLI
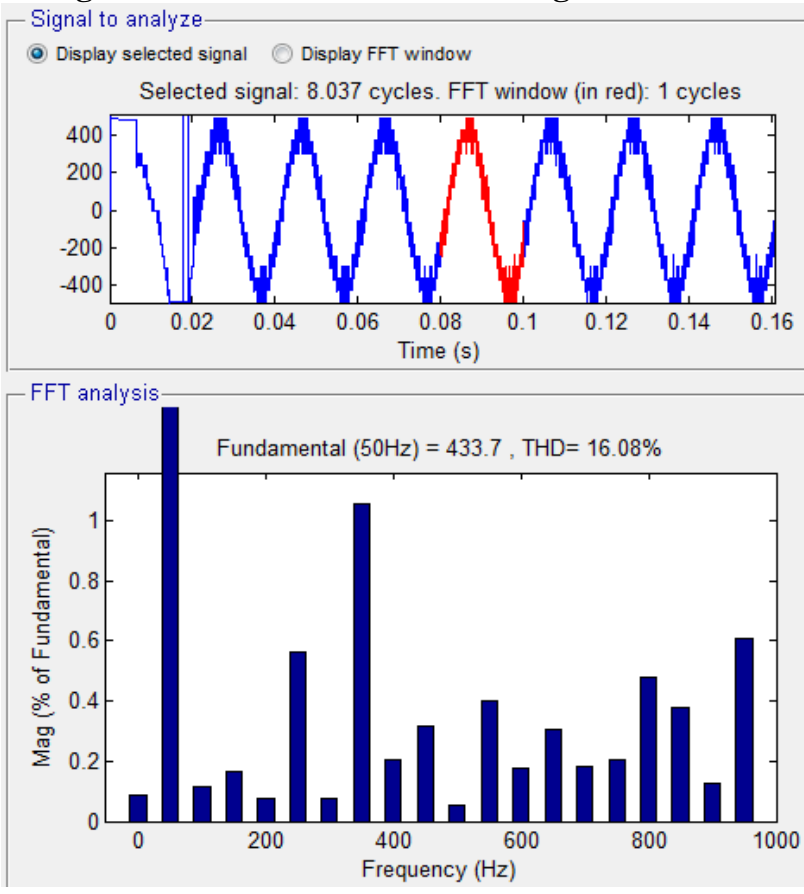

Figure 14: THD in line voltage of DCMLI
Figure 13 illustrates three-phase line voltages of diode clamped inverter. Peak magnitude of line voltage in three phases is $500 \mathrm{~V}$.. Harmonic analysis in line voltage signal is shown in figure 14. FFT window displayed shows $16.08 \%$ distortion in line voltage of DCMLI.

\section{B. PMSM with variable speed}

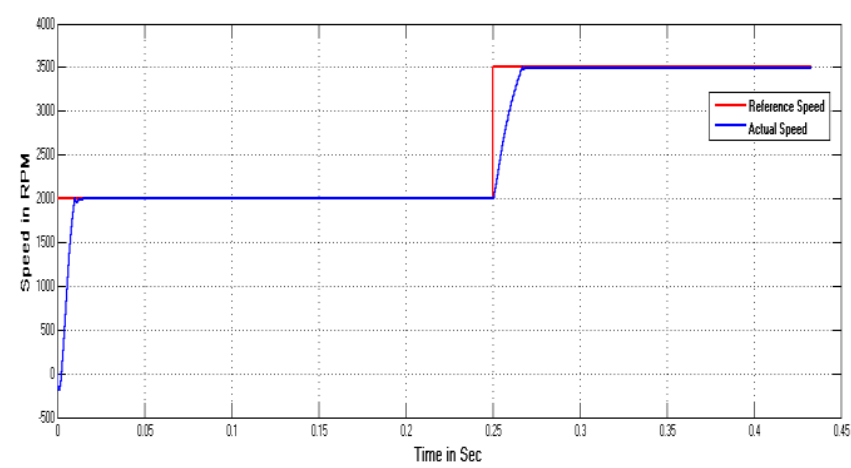

Figure 15: Speed of PMSM drive

Speed of PMSM running with variable speed condition is shown in figure 15. Reference speed signal (green) and the actual speed (blue) signal are shown in figure 15. The actual speed follows the reference speed as shown in figure. Initial PMSM run speed reference value is set to 2000 RPM and PMSM follows the set speed and continues to run at 2000 RPM. At time 0.25 seconds, reference speed command is set to 3500 RPM. The closed-loop speed control sets PMSM to follow the reference speed command and hence after 0.25 seconds PMSM speed rises to 3500 RPM and follows reference speed.

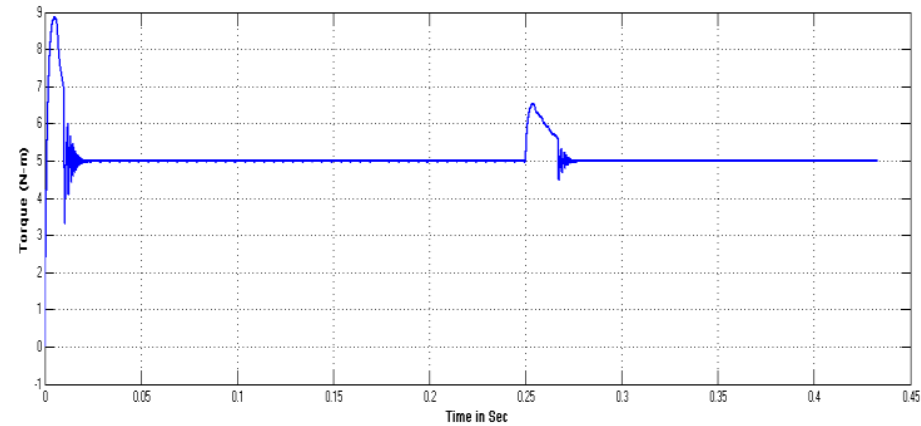

Figure 16: Torque of PMSM drive

Figure 16 shows the torque of PMSM. PMSM generates torque of $5 \mathrm{~N}-\mathrm{m}$ corresponding to speed at which rotor of PMSM rotates. After initial transient in torque, the signal remains constant with $5 \mathrm{~N}-\mathrm{m}$. At speed variation command at 0.25 seconds, with slight disturbance, torque settles at $5 \mathrm{~N}-\mathrm{m}$ again. Figure 17 illustrates three-phase stator currents of PMSM. Three-phase PMSM stator coils draws 10A current. Magnitude in three phases of stator coils remains with constant peak. As speed change command is given at 0.25 seconds, the frequency of the stator currents increases with the same 10A peak. As the speed in synchronous machines varies with frequency with constant number of stator poles, PMSM stator current frequency increases after speed is increased from 2000RPM to 3500RPM at 0.25 seconds. Harmonic distortion FFT window of stator current is shown in figure 18 . Stator current is distorted by $2.36 \%$ and is well within nominal distortion limit.

Published By: 


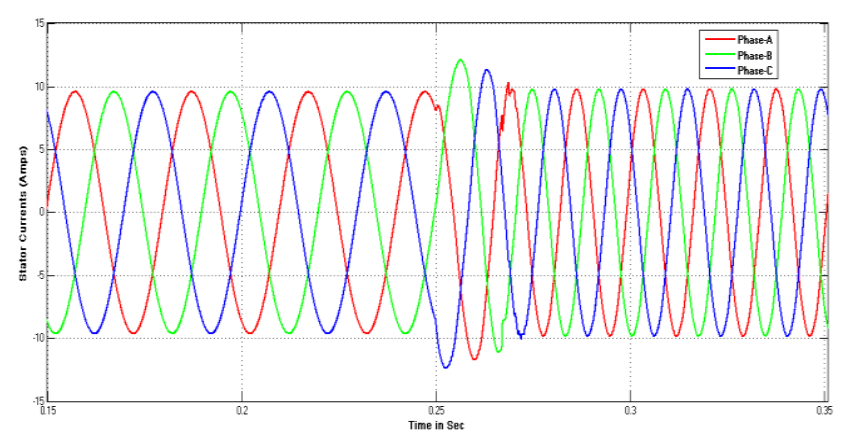

Figure 17: Three-Phase stator currents of PMSM
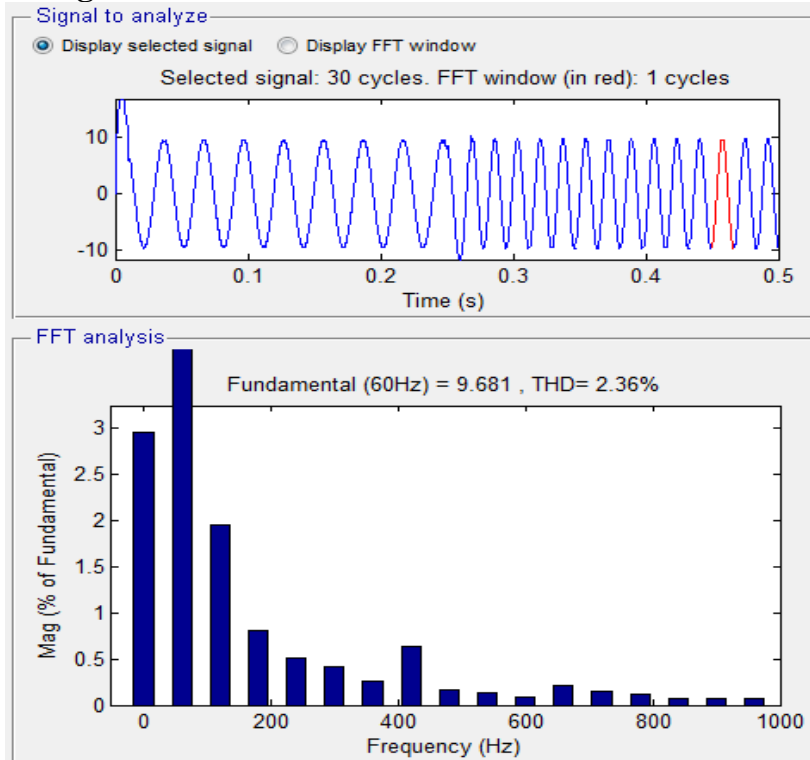

Figure 18: THD in stator current

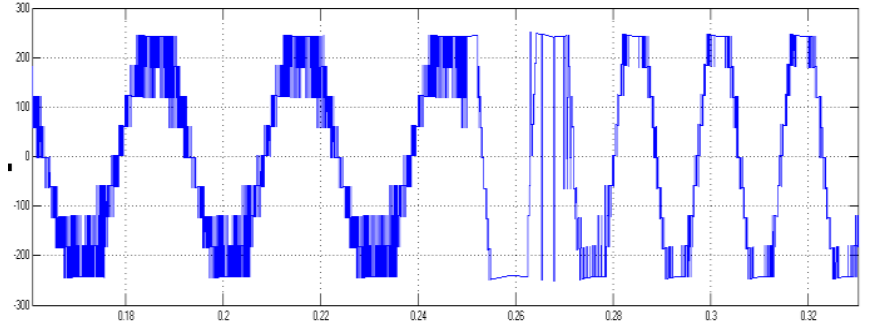

Figure 19: Three-Phase voltages of DCMLI
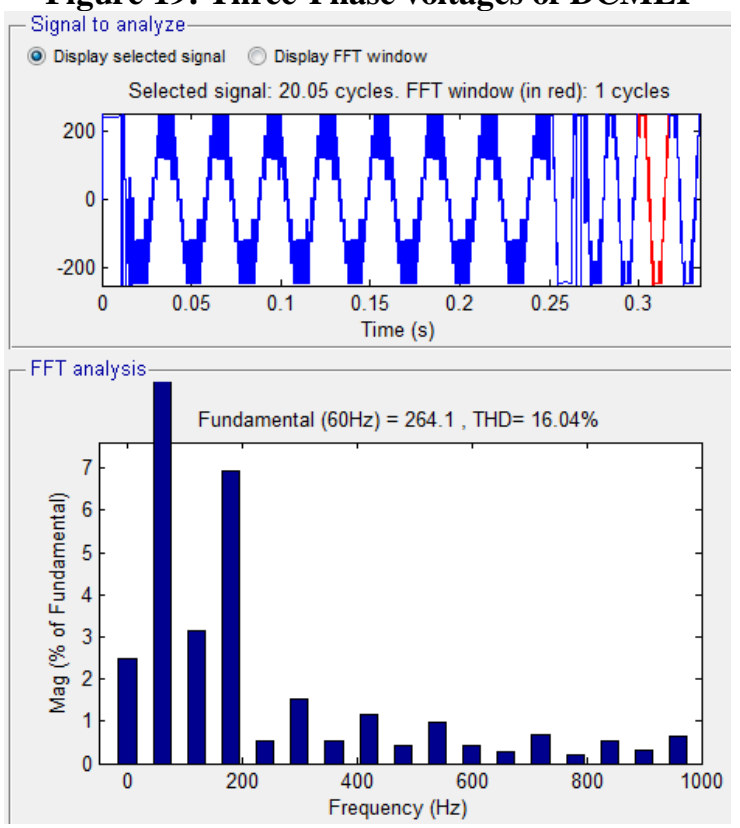

Figure 20: THD in phase voltage of DCMLI

Figure 19 illustrates three phase voltages of diode clamped inverter. Phase voltage is leveled with nine magnitudes yielding nine-level voltage signal. Peak magnitude of phase voltage in three phases is $250 \mathrm{~V}$. As speed change command is given at 0.25 seconds, the frequency of the phase voltages in DCMLI increases with the same peak magnitude. As the speed in synchronous machines varies with frequency with constant number of stator poles, PMSM phase voltage frequency increases proportionally after speed is increased from 2000RPM to 3500RPM at 0.25 seconds. Harmonic analysis in phase voltage signal is shown in figure 20. FFT window displayed shows $16.04 \%$ distortion in phase voltage of DCMLI.

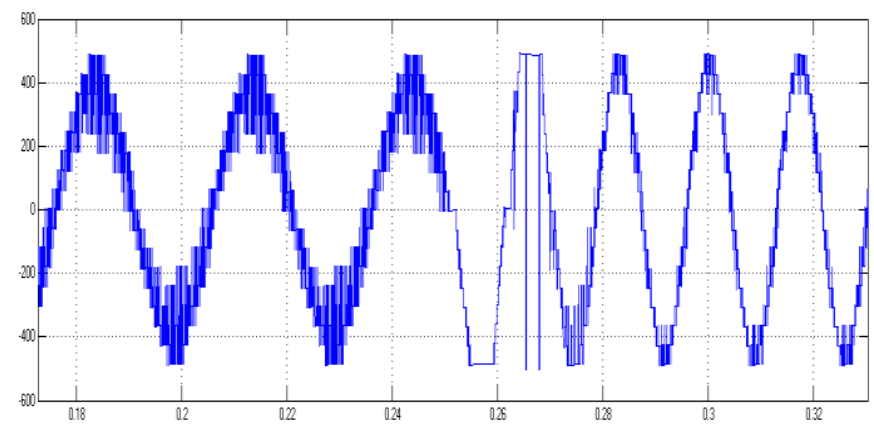

Figure 21: Three-Phase Line voltages of DCMLI
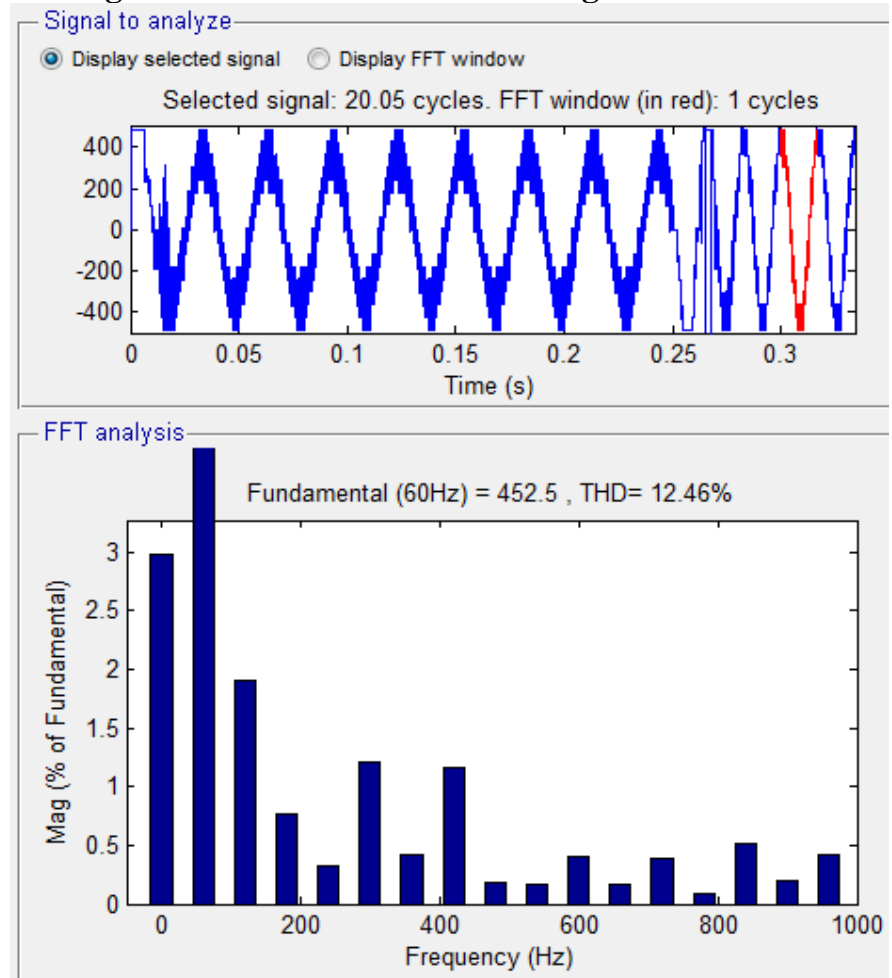

Figure 22: THD in line voltage of DCMLI

Figure 21 illustrates three-phase line voltages of diode clamped inverter. Peak magnitude of line voltage in three phases is $500 \mathrm{~V}$. Phase-A is illustrated in red colour, phase-B in green and phase- $\mathrm{C}$ in blue colour. As speed change command is given at 0.25 seconds, the frequency of the line voltage of DCMLI increases with the same peak magnitude. As the speed in synchronous machines varies with frequency with constant number of stator poles, PMSM line voltage frequency proportionally increases after speed is increased from 2000RPM to 3500RPM at 0.25 seconds. Harmonic analysis in line voltage signal is shown in figure 22. FFT window displayed shows $12.46 \%$ distortion in line voltage of DCMLI. Table III illustrates the comparison of harmonic distortion analysis in different modes of PMSM 
operation with different levels of DCMLI [12], [13].

Table III: THD comparison

\begin{tabular}{|c|c|c|c|}
\hline Level & THD & $\begin{array}{l}\text { Fixed } \\
\text { Speed } \\
\text { mode }\end{array}$ & $\begin{array}{c}\text { Variable } \\
\text { Speed mode }\end{array}$ \\
\hline \multirow{3}{*}{ 9-Level } & $\begin{array}{c}\text { Stator } \\
\text { current of } \\
\text { PMSM }\end{array}$ & $0.26 \%$ & $2.36 \%$ \\
\hline & $\begin{array}{c}\text { Phase } \\
\text { voltage of } \\
\text { inverter }\end{array}$ & $18.71 \%$ & $16.04 \%$ \\
\hline & $\begin{array}{c}\text { Line } \\
\text { voltage of } \\
\text { inverter }\end{array}$ & $16.08 \%$ & $12.46 \%$ \\
\hline \multirow{3}{*}{ 7-Level } & $\begin{array}{c}\text { Stator } \\
\text { current of } \\
\text { PMSM }\end{array}$ & $1.27 \%$ & $2.36 \%$ \\
\hline & $\begin{array}{c}\text { Phase } \\
\text { voltage of } \\
\text { inverter }\end{array}$ & $23.47 \%$ & $31.35 \%$ \\
\hline & $\begin{array}{c}\text { Line } \\
\text { voltage of } \\
\text { inverter }\end{array}$ & $20.8 \%$ & $23.38 \%$ \\
\hline \multirow{3}{*}{ 5-Level } & $\begin{array}{c}\text { Stator } \\
\text { current of } \\
\text { PMSM }\end{array}$ & $0.26 \%$ & $2.36 \%$ \\
\hline & $\begin{array}{c}\text { Phase } \\
\text { voltage of } \\
\text { inverter }\end{array}$ & $26.38 \%$ & $45.37 \%$ \\
\hline & $\begin{array}{c}\text { Line } \\
\text { voltage of } \\
\text { inverter }\end{array}$ & $23.15 \%$ & $35.40 \%$ \\
\hline
\end{tabular}

\section{CONCLUSION}

PMSM drives are becoming very good option for industrial and agricultural applications these days. The paper analyzes nine-level inverter fed PMSM drive with fixed and variable sped operations. Closed loop control with PI controllers is analyzed with fixed and variable speed conditions. With the simple closed-loop speed control technique, actual speed follows the reference speed with both fixed speed condition and also with variable speed condition which is validated with simulation results. DCMLI operation with switching sequence is explained. Pulses to DCMLI are generated from PWM generator using LSCPWM pattern. Reference signal obtained from speed control is compared with high frequency carrier signal to generate gate pulses to DCMLI switches. The control strategy is validated for fixed speed and variable speed condition.

\section{REFERENCES}

1. R. Krishnan, "Permanent Magnet Synchronous and Brushless DC Motor Drives," CRC Press, Taylor and Francis Group. ISBN-978-0-8247-53849

2. Paul C.Krause, Oleg Wasynczuk, Scott D.Sundhoff, "Analysis of Electric Machinery and Drive Systems," IEEE Press Power Engineering society ISBN-0-471-14326-X

3. H,Madadi Kojabad, G.Ahrabian, "Simulation and analysis of the interior permanent magnet synchronous motor as a brushless AC-drive," Science direct / Simulation practice and theory $7(2000)$ 691-707
4. Pragasan Pillay, R.Krishnan." Modeling of Permanent Magnet Motor Drives", IEEE vol.35,no.4,november 1988

5. R. Dhaouadi, N. Mohan and L. Norum, "Design and implementation of an extended Kalman filter for the state estimation of a permanent magnet -50 I synchronous motor," IEEE Trans. Industrial Electronics, vol. 6, no. 300.10 .20 .30 .4 0.50 .60 .70 .80 .91 Jul. 1991, pp.491 497.

6. K. Rajashekara, A. Kawamura and K. Matsuse, "Sensorless control of AC motor drives", New York: IEEE Press, 1996.

7. G. Sree Lakshmi, S. Kamakshaiah and T. R. Das, "Closed loop PI control of PMSM for hybrid electric vehicle using three level diode clamped inverter for optimal efficiency," Energy Efficient Technologies for Sustainability (ICEETS), 2013 International Conference on, Nagercoil, 2013, pp. 754-759.

8. L. Samaranayake, Y. K. Chin and U. S. K. Alahakoon, "Distributed control of permanent magnet synchronous motor drive systems," Power Electronics and Drive Systems, 2003. PEDS 2003. The Fifth International Conference on, 2003, pp. 710-715 Vol.1.

9. H. H. Lee and U. H. Jeong "A Study on Speed Synchronization for Multi Motors using Controller Area Network" IEEE Trans. Ind. Appl., vol. 44 no. 42000.

10. L. Feng Y. Koren and J. Borenstein "Cross-Coupling Motion Controller for Mobile Robots" IEEE Trans. on Control Systems Technology, vol. 1 December 1993.

11. R. Sasidhar, Dr. A. Lakshmi Devi, "Analysis of Five-Level Diode Clamped Multi-

12. Level Inverter Fed Permanent Magnet Synchronous Machine Drive" Jour of Adv Research in Dynamical \& Control Systems, Vol. 10, 07-Special Issue, 2018, pp. (220-233)

13. R. Sasidhar, Dr. A. Lakshmi Devi, "Speed Control Analysis Of Lscpwm Driven Seven-Level Inverter Fed Permanent Magnet Synchronous Motor Drive", ARPN Journal of Engineering and Applied Sciences, VOL. 14, NO. 1, JANUARY 2019, pp 299-306.

\section{AUTHORS PROFILE}

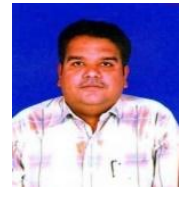

Mr. R. Sasidhar is a Full - Time research schola pursuing his $\mathrm{Ph}$. D in Department of EEE, Sri Venkateswara University, Tirupati since 2016. He received his $\mathrm{M}$. Tech degree from JNTU-Hyderabad in 2010. He received his B. tech degree from JNT University, Kakinada in 2000.

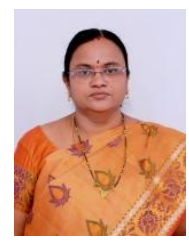

Dr. A. Lakshmi Devi is a Professor in the Department of Electrical and Electronics Engineering, Sri Venkateswara University, Tirupati. She received her Doctoral Degree from the same University in 2008. She received her Master's Degree from IISc Bangalore in 1993. She received her B. tech from Sri Venkateswara University in 1991. She has 23 years of experience in teaching field. 